\title{
The experience of student midwives being taught newborn infant physical examination (NIPE) as an extracurricular activity at a university in the UK: A Descriptive Survey Study
}

\section{Abstract:}

Although newborn infant physical examination has been part of midwifery practice in the United Kingdom for several decades, very few undergraduate programmes incorporate the theory and practice of newborn examination within the midwifery curriculum. Qualified midwives therefore, often develop this knowledge and these skills as part of their continuous professional development. This paper explores the experience of undergraduate midwifery students being taught newborn infant physical examination knowledge, skills and competencies as an extra-curricular activity alongside qualified midwives. Newly qualified midwives involved with the initiative undertook an online survey which consisted of a mixture of closed and open questions which allowed the expansion of some answers with open text. The qualitative data was explored by thematically analysing the responses. This small study demonstrates the feasibility of providing newborn infant physical examination as an extra-curricular activity to students undertaking a standard undergraduate midwifery programme. All participants agreed that this learning should be undertaken whilst still a student. The benefits identified were for the midwife herself including women and NHS employers. Midwives felt their confidence, knowledge and skills around neonatal issues had increased, women experienced better continuity of care and employers benefitted from the increased number of professionals who could undertake this assessment.

\section{Key words:}


Extra-curricular activity, newborn infant physical examination, student midwives, undergraduate midwifery curriculum

\section{Introduction}

Although newborn infant physical examination (NIPE) has been part of midwifery practice in the United Kingdom (UK) for several decades, very few undergraduate midwifery programmes incorporate the theory and practice within the curriculum (Yearly et al. 2017) meaning that qualified midwives often develop the knowledge and skills as part of their continuous professional development (CPD).

This article explores the experience of undergraduate midwifery students being taught the NIPE knowledge, skills and competencies alongside qualified midwives, as an extracurricular activity (ECA) in a University in the South of England.

\section{Background:}

Examining the newborn soon after birth is an important aspect of the midwives' role (Nursing \& Midwifery Council [NMC] 2015). The purpose is to exclude and/or identify any obvious anomalies and provide reassurance to parents about the wellbeing of their baby (National Institute for Health and Care Excellence [NICE], 2006). This initial check is usually performed by the midwife within an hour of the birth (NMC, 2015) and a second more detailed examination, often referred to as the 'medical' or 'discharge' examination (Hall and Elliman, 2006) but more recently, as NIPE (Public Health England [PHE], 2016), occurs between six and 72 hours (Davis and Elliman, 2008), This examination has more of a screening role offering a detailed scrutiny of the newborn infant in order detect less obvious adverse conditions in four main areas, the heart, hips, eyes and testes. 
In the UK NIPE was traditionally a doctor's role (Hall, 1999). However, with the reduction in junior doctor's hours (Townsend et al. 2004) traditional role boundaries became blurred, including who performed the NIPE (Lomax, 2001). Simultaneously, there were calls to improve continuity of midwifery care and carer for women (Department of Health [DOH], 1993; 2007). This coincided with a strong drive to reduce the medicalisation of childbirth and frame it more within a social model (Ireland and van Teijlingen, 2013). Following these initiatives, midwives became more involved in undertaking the NIPE, supporting the philosophy of care of placing the woman and her baby at the centre of midwifery practice (Davies, 2008).

Any extension to the role should also be supported by defined competencies and appropriate education and assessment, as well as be within the scope of practice of the midwife (NMC, 2009). The education and training of midwives to undertake NIPE safely and effectively has led to a number of universities in the UK to develop and deliver programmes for midwives to become competent in this role (Rogers et al. 2017).

\section{Lit review}

A review was undertaken to determine whether any studies outlining the provision of NIPE within pre and post registration midwifery modules had previously been explored. A search strategy was therefore designed to identify the relevant literature and the following databases were used: CINAHL Complete with full text and peer reviewed, Academic Search Ultimate, Science Direct, OVID, PubMed, Complementary Index and Google Scholar. Key search words and Boolean terms included, but not limited to: newborn examination, neonatal assessment, newborn infant physical examination, physical examination, infant, newborn AND midwifery, education, pre-registration, students, undergraduate, student role AND curriculum, 
skills, competencies. Various combinations of terms were utlised. Papers were included from the last 25 years as midwives began to examine newborn babies from 1995 onwards. Articles also had to be in the English language to ensure accurate interpretation of data by the researcher. Following screening over 10,000 articles were retrieved. Articles were excluded due to lack of relevance (for example, examination of piglets), repetition, not written in English or research that was just relevant to examination of the newborn in general. The final search revealed just five articles ranging from 2017-2019 (Jones and Furber, 2017; Rogers et al. 2017; Yearley et al. (2017); McDonald, 2018; Stanyer and Hopper 2019). One further unpublished survey from a trusted source (in main author's archive) was included as it surveyed higher institutions in England on their provision of training around examination of the newborn and was the first to do so (McFadden and Paterson 2005).

\section{Post-registered training:}

Initially, programmes were set up to target midwives who had been practising for several years. McFadden and Paterson in 2005 undertook to establish the extent and type of training for midwives and nurses to perform routine examination of the newborn in England. An online questionnaire was developed and emailed to higher education institutes (HEIs) $(n=27)$ who were identified as providing training for midwives to undertake this role. The final response rate was 13 with the researchers concluding there was a wide variation in the educational provision of the course, for example, what theoretical components were included, and how many examinations were required (McFadden and Paterson 2005). Similar findings were obtained within a more recent study undertaken by Rogers et al (2017) which aimed to assess the scope and practice of NIPE education across all HEI midwifery curricula in the UK. 
Their results indicated that NIPE education for midwives is well-liked and fully established within post-registration modules, although again, variations existed in the length, content, assessment, levels of study and credits awarded (Rogers et al 2017). Both studies argue for the importance of a standardised NIPE programme across the UK.

\section{Pre-registered training:}

More recently, the NIPE knowledge and skills are slowly being incorporated into undergraduate midwifery programmes, a step which has already been taken by countries such as New Zealand and Australia (Midwifery Council of New Zealand, 2015; Stanyer and Hopper 2019). However, in Australia, students are required to have experience in undertaking 20 full examinations of a newborn infant but accreditation standards (Australian Nursing and Midwifery Accreditation Council, [ANMAC] 2014) do not specify whether these examinations incorporate aspects of NIPE such as examination of the hips, red reflex in the eyes and so on. Currently in the UK, as there is no national standard to mandate for the education of NIPE in the undergraduate programme (Stanyer and Hopper 2019), therefore different models are emerging, ranging from all the content being taught and assessed (Yearley et al. 2017 ; ) to one where only the theory and not the practice is taught, and some not at all (Jones and Furber, 2017).

Of the 58 educational institutions surveyed by Yearley et al. (2017), a quarter (25.0\%) stated that NIPE training is included in the pre-registration midwifery programmes with $30 \%$ indicating they had no plans to integrate NIPE within the undergraduate curriculum. Despite the reported benefits (practice partners, commissioners, students and childbearing women) challenges were also highlighted, 
such as resources and support for students within the practice placement areas (Yearley et al. 2017). Stanyer and Hopper's (2019) findings are comparable. Finally, McDonald's (2018) grounded theory study which explored factors that motivated midwives to undertake NIPE as a post registration midwifery course concluded that most participants who participated within the study agreed that NIPE training should be integral to the pre-registration midwifery curriculum. Integration at undergraduate level helps to dispel the notion that midwives need to be advanced or specialist practitioners to perform NIPE (Blake 2012, Jones and Furber, 2017).

In response to the general consensus identified in the literature that undergraduate midwifery students would benefit from receiving NIPE education and training before qualification, a university in the South of England explored two different models in an attempt to achieve this. The first was an innovative approach that supported a few students to complete the NIPE programme as an ECA with the aim to be fully qualified NIPE practitioners at the same time they completed their undergraduate programme. Teaching and learning took place alongside qualified practitioners who were accessing the programme as part of their continuous professional development (CPD). Local Heads of Midwifery were supportive of this initiative as it would potentially increase the number of NIPE examiners in the workforce without requiring releasing staff to attend a formal programme of learning. This study reports on the above model.

The second model was embedding the knowledge and skills within the undergraduate curriculum, but without any assessment of competence. The rationale for this model was due to the limited number of NIPE examiners in practice that would be required to assess a large cohort of students. An evaluation of this second model will be reported on in a further article. 


\section{Outline of how the extracurricular programme was delivered}

The NIPE elements are taught within a CPD module, which is offered three times a year. Theoretical learning takes place two days per month over a six-week period (five taught days in total) with a sixth day dedicated to individual summative presentations. The practical skills (a minimum of 10 supervised newborn examinations and one summative assessment) are completed within nine months of commencing the module.

The undergraduate timeline was slightly different in order to facilitate completion of the NIPE module no later than completing their undergraduate studies. The other difference was the number of practical examinations they had to carry out due to their limited experience and exposure to the newborn. Students were required to undertake 30 complete examinations, of which 20 were under direct supervision, nine under indirect supervision with the agreement of their mentor and the final examination was assessed by the module lead and the student's mentor.

At the end of their second year, students were offered the opportunity to undertake the NIPE module described above. Due to capacity within the CPD module only five students per cohort could be accommodated. Students were invited to self-select against a set of criteria (Table 1). Within each cohort of students there were many more volunteers than spaces, so names were then randomly selected to take part.

You must be on target to achieve all your programme requirements (i.e. no academic or practice assessment referrals in the $2^{\text {nd }}$ year)

Your normal undergraduate practice placement must be within a clinical environment that facilitates midwives to undertake NIPE

You cannot use the extra 20 academic credits obtained from completing the extra-curricular activity to compensate for a failed unit within the undergraduate programme

You must recognise and understand the unit will be an added demand to your established undergraduate pre-registration 
programme and cannot be used as mitigation against workload and late submission of academic or practice assessments.

You can only practice the extended role independently, following successful completion and registration with the regulatory body

Table 1: Criteria for student self-selection

\section{Aim and Objectives of the study}

The overall aim of the study was to evaluate the impact and effectiveness of offering NIPE knowledge and skills to undergraduate student midwives as an extra-curricular activity.

To achieve the aim the following questions were asked:

1. Can newborn infant physical examination knowledge, skills and competence be delivered effectively outside of a standardised academic curriculum to undergraduate midwifery students?

2. How were newly qualified, NIPE competent midwives viewed by employers at the time of recruitment and selection?

3. Are the newly qualified midwives facilitated to maintain their NIPE competencies during their first employment?

The objectives were: i) to understand the student experience of being taught NIPE knowledge, skills and competencies and applying these in clinical practice, ii) to explore the impact of newly qualified midwives who were NIPE competent at the point of registration and; iii) what strategies do employers have in place to facilitate newly qualified midwives to maintain their knowledge and skills.

\section{Programme Delivery:}

\section{Method}

This study adopted a descriptive survey design (Sue and Ritter 2012) using an online questionnaire that was co-created by the researchers using the Bristol On-line Survey (BOS) tool (https://www.onlinesurveys.ac.uk). The survey was designed and 
developed based on the limited existing literature and was shared for review and feedback by consulting with a small group of undergraduate student midwives interested in NIPE. In addition, a colleague with expertise within quantitative methodologies was approached and asked to critically review the tool. Questions were arranged into three main areas, i) undergraduate experience, ii) recruitment and selection for employment and iii) practice as a qualified midwife. A mix of closed and open questions were utilised which allowed the expansion of some answers with open text (Appendix 1).

\section{Sample}

Participants invited to take part in the survey were all newly qualified midwives $(n=13)$ who undertook the NIPE extracurricular programme and were in contact with the NIPE module lead via a social media site. Invitations were sent out through this medium. A reminder was posted two weeks after the initial request to participate as an attempt to increase the response rate (Edwards et al 2009).

\section{Data Analysis}

The quantitative survey data was analysed using the BOS analysis function. This function generates descriptive data, which enables the categorisation and description of information (McCue 2015). As the sample size was known to be small the data was analysed using descriptive statistics only (Sue and Ritter 2012) as any inference regarding causal relationships between variables would require much larger numbers (Sue and Ritter 2012). The qualitative data from the open questions was explored by thematically analysing the responses within each question which were then grouped into common themes (Holloway 2008). Initially this was undertaken independently by the two researchers in order to increase trustworthiness in the results (Creswell and Poth 2018). 


\section{Ethical considerations}

Ethical approval was received from the University Research Ethics Committee: No.15392. Both authors were known to the participants in their capacity as module lead and as midwifery lecturers. The decision was therefore made to use an online survey to help ensure that the participants' responses were anonymous to the researchers (Sue and Ritter 2012). Participants were guided on the landing page of the survey to read the instructions which outlined that their participation was voluntary, and they would not be identifiable. Their role as a midwife would not in any way be affected should they decide not to participate. They were advised that they were free to withdraw at any point, without reason, prior to submitting the questionnaire. Participants confirmed their consent to participation on the landing page.

\section{Results:}

Results are reported in relation to each of the areas the questions were arranged under. The qualitative data from the free text responses in the questionnaire was undertaken using thematic analysis. The free text responses were given by the participants to either expand, clarify or introduce new information to their formatted response. This meant the responses were short and fragmented and so did not warrant in-depth analysis via a particular theoretical framework.

Responses were received from eight out of a possible 13 midwives (62\%). Sample size was determined by the size of those undertaking the ECA, therefore only participants who graduated with NIPE as an ECA were eligible, resulting in a small study pool. 
One respondent attended the module but did not complete the practical elements due to a lack of available mentors but inclusion of their data regarding the impact and effectiveness of offering NIPE knowledge and skills was still thought to be important. All participants were practising midwives at the time of responding to the survey.

\section{Undergraduate experience}

Firstly, the participants were asked to use the open text box and name three things they enjoyed about undertaking the NIPE module. All participants completed this and the following two themes were identified: i) Enhancing knowledge and ii) Shared learning.

\section{i) Enhancing knowledge:}

This theme centred mainly around participants obtaining a deeper learning around newborn anatomy and physiology as the following quotes demonstrate:

"Expanding knowledge (both physiological and pathological) about the newborn baby" (NQM 1)

"Being given the opportunity to undertake further learning regarding the physiology of the newborn - it was enlightening and underpinned knowledge from the Midwifery degree" (NQM 3)

"Learning about the newborn in a much more detailed way" (NQM 2)

\section{ii) Shared learning:}

In this theme participants commented on the benefits of learning alongside their qualified practitioners: 
"The way in which the programme was delivered alongside registered midwives was great as they bought a wealth of knowledge and expertise" (NQM 3)

"Attending lectures with qualified midwives really enhanced learning and satisfaction" (NQM 4)

When asked to identify three things that were challenging about undertaking the NIPE module as a student, a further two common themes were also identified: i) Logistics of doing the module and ii) Lack of support

\section{i) The logistics of doing the module:}

The logistics of doing the module was not just confined to finding the time to attend and complete the theory and practice assessment, but also included the distance some students needed to travel. The structure of the undergraduate programme is such that taught elements are delivered on two campus sites, some distance apart. However, to facilitate the shared learning with qualified midwives, this needed to take place on one campus site only, hence the need to travel further than normal.

"The distance I had to travel and no help with expenses from [location removed]" (NQM 2)

Other students struggled to fit in the extra academic study that was required including the practical assessments:

"Trying to complete the minimum required NIPEs alongside standard degree placements/essays/fitting in with mentor timetables - this coordination could often be difficult" (NQM 4)

"Finding time to a heavy academic calendar to complete the academic work, which was stressful at times" (NQM 8)

“Difficult to juggle extra studies/exam during the degree" (NQM 5)

\section{ii) Lack of support}


Students were required to gain the support from their Head of Midwifery prior to undertaking the module to ensure completion. However, two main issues were identified which impacted on the student's ability to undertake the required practical examinations: a lack of organisational support whilst in placement and a perceived lack of support from qualified midwives. These issues are reflected within the quotes below:

"The lack of support from my Trust to enable me to gain clinical experience" (NQM 2)

"Getting support of my own trust for practice opportunities" (NQM 6)

"Fitting extra hours in alongside normal placement to get all of the examinations in as on a normal postnatal or labour ward shift the priorities were not the NIPES" (NQM 8)

"I occasionally felt that some midwives in practice were not very accepting of me as a student performing NIPE [...]" (NQM 4)

"RM's reactions to coming out of university "more qualified" than them, there was some negativity [...]" (NQM 7)

Next the participants were asked to rate their experience of sharing the classroom learning with qualified midwives. The responses indicate that at the time, most student midwives gained from this experience. All $(n=8)$ either agreed or strongly agreed that they took the opportunity to integrate with the midwives and also learn more about their role. Five of the students felt there should have been more shared learning, with only one student identifying they felt intimidated by this type of learning environment.

The participants were asked to rate their experiences of achieving NIPE skills and competencies in practice. All the students either agreed or strongly agreed that the clinical area was supportive of them undertaking the NIPE module (Table 2) and seven found the midwives helpful in facilitating their experience. Three students did 
however, have difficulty in finding a midwife to mentor them and to also sign off their skills and competencies.

\section{In colour please}

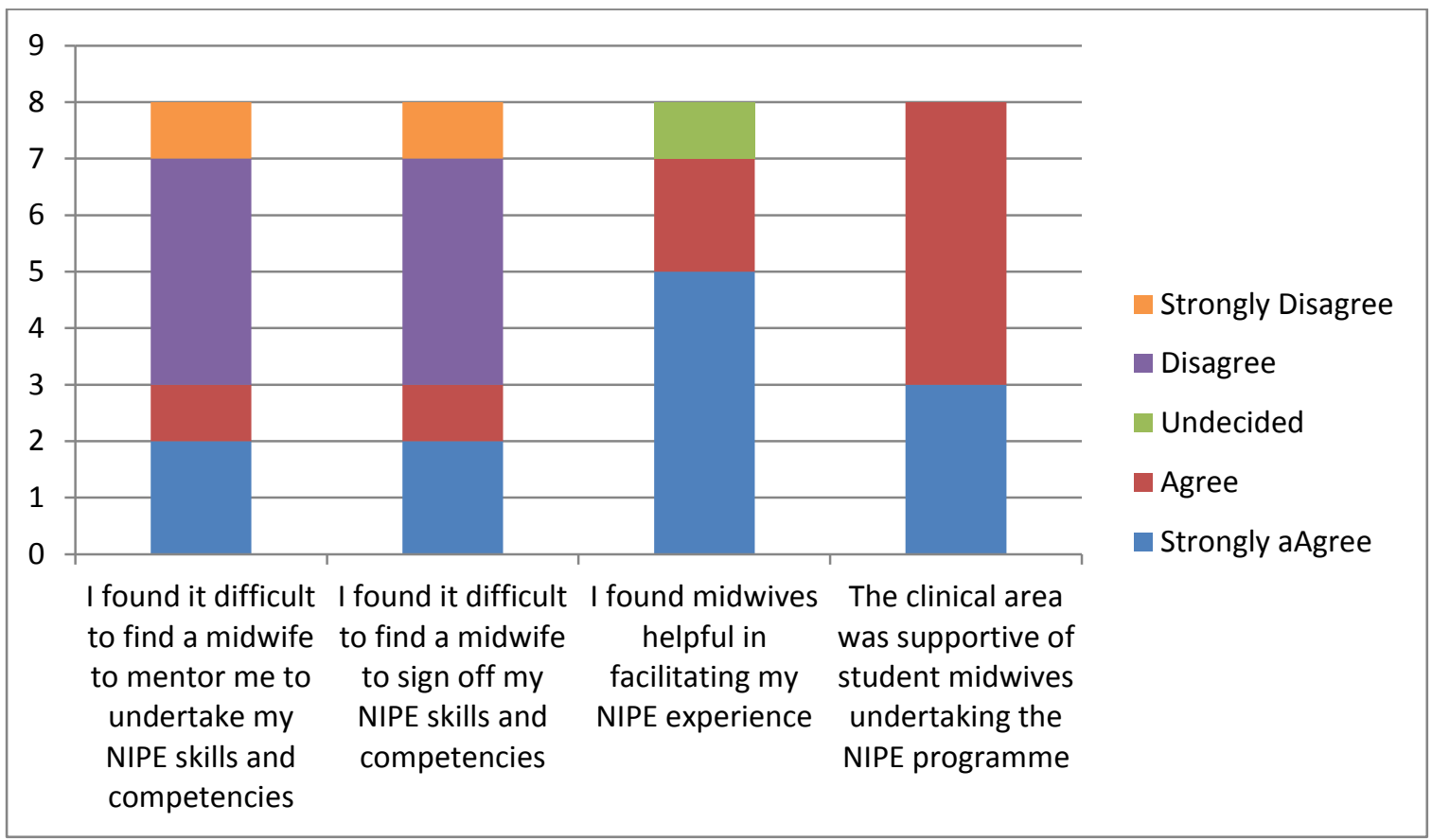

Table 2: Experiences of achieving NIPE skills and competencies in practice

Finally, in this section the participants were asked if they would recommend completing NIPE knowledge, skills and competencies while still a student midwife. All eight students agreed they would.

\section{Recruitment and selection for employment:}

Participants were asked to comment on the recruitment and selection process when applying for their current post (Table 3). Seven participants reported that they included the qualification on their CV. At interview only five participants were asked direct questions about NIPE by the interview panel, but all the respondents identified that they had initiated a discussion. Six reported believing that having the NIPE knowledge and skills was an advantage at their interview.

\section{In colour please}




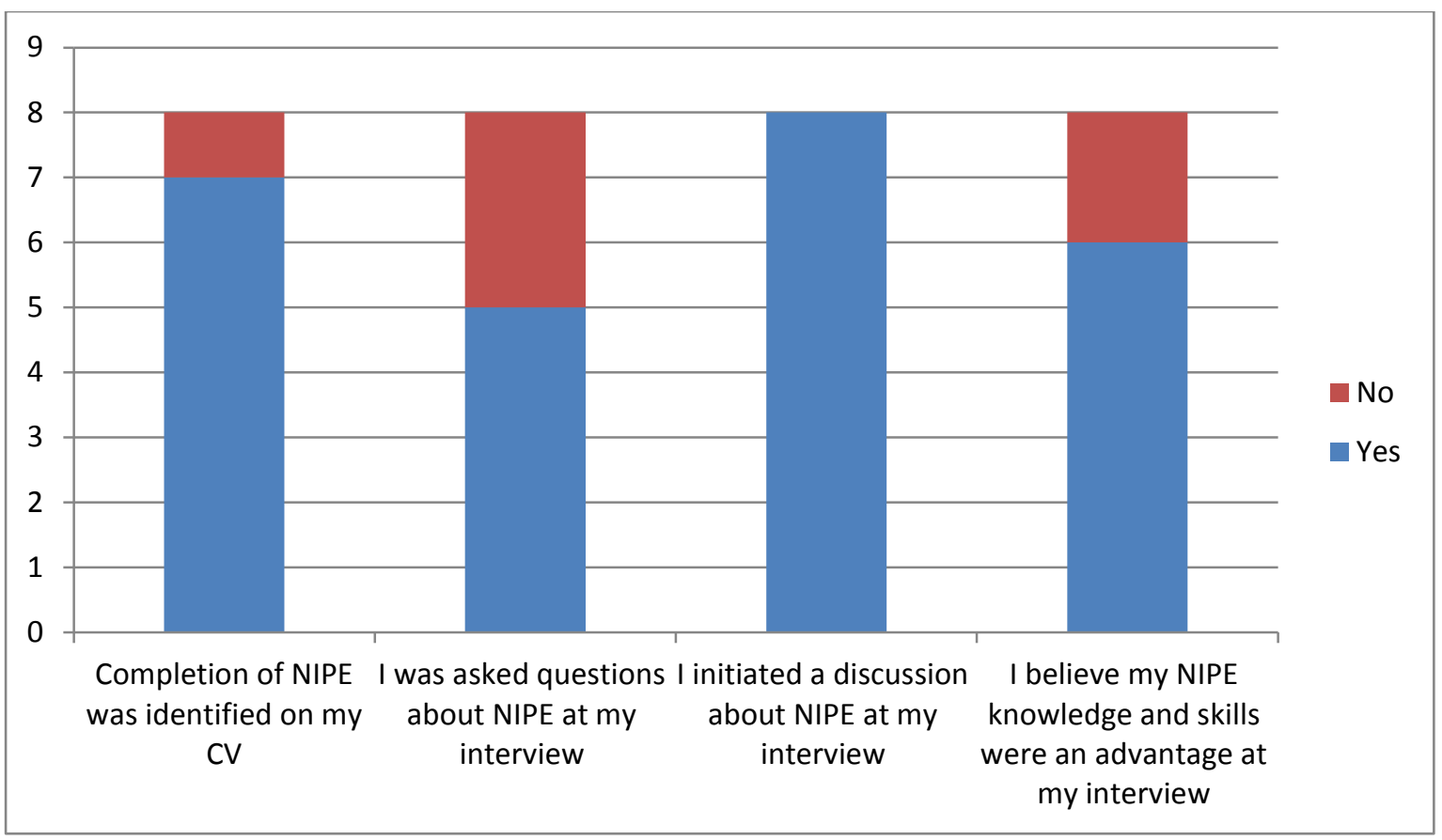

Table 3: Recruitment and selection

\section{Practice as a qualified midwife}

\section{Benefits}

Participants were asked whether in their opinion being NIPE trained had benefited them as a registered midwife, seven answered yes to the question and one disagreed. All eight participants expanded on their responses. The following themes relate to benefits as identified by the students: i) increased confidence; ii) continuity of care(r); iii) new skills. .

\section{i) Increased confidence}

Newly qualified midwives felt their confidence had increased by being able to answer questions asked by parents knowledgeably:

"It has helped me in teaching students how to handle babies more appropriately and what to look out for. I can also more confidently answer questions relating to the baby directed by parents" (NQM 7)

"Even though I did not complete the course; much of the new knowledge I learnt on the course has enabled me to make stronger decisions and conversations with colleagues and parent.... I use some of the skills learnt in my initial new born check at delivery of babies" (NQM 2). 


\section{ii) Continuity of care( $r)$;}

In this theme the participants clearly stated the benefits of being able to provide continuity of care(r) to women in their caseload including helping the unit and their colleagues:

"I am able to offer continuity of carer; in some cases being able to give antenatal care, facilitate the birth, NIPE and complete postnatal discharge... absolute magic!" (NQM 6).

"I am now a community midwife at a MLU [midwife-led unit] and having the skills to perform EXONs provides better continuity to women and enhances the team by being able to help with their caseload where EXONs are required. NQM" 4

"I am able to offer better care to families and their babies. Being registered [NIPE trained] also benefits the unit I work for" (NQM 1).

\section{iii) New skills:}

This quotes within this theme clearly highlights that the participants were pleased to have gained new skills and used them to benefit women in their care including supporting other midwives in NIPE.

"I also really enjoy doing EXONs and am so grateful to have had the opportunity as a student to be equipped with these skills" (NQM 4)

"I am also called upon by other midwives to check babies if they are unsure as they rely on my additional skills undertaken" (NQM 5)

One participant responded that her current employers did not encourage the use of her skills which she found disappointing

"The trust I am employed at does not appear to encourage midwives to undertake EXON at work which is disappointing. I have asked on several occasions for support to integrate EXON into my practice but nothing has come of it' (NQM 3) 


\section{Barriers}

When asked if they experienced any barriers to utilising the knowledge and skills at the commencement of their first job the majority of participants responded that they did not.

"My [NIPE] manager at my trust was delighted that I was trained as a student and gave me extra support to adjust to doing NIPE as a newly qualified midwife" (NQM 4)

"My first job thoroughly embraced my skills and I performed NIPE clinics at least once-twice weekly" (NQM 1)

Barriers were described by three participants. One stated that they were working on the labour ward where the skills could not be utilised. The second commented that she had to undertake further competency assessments by a paediatrician, which was not facilitated and the third was the newly qualified midwife who did not complete the module.

"The Trust at first insisted I undertook NIPE alongside the paediatric registrar (who does not undertake routine NIPE) so they could be sure I could undertake it competently. There were no provisions for this however, and I have not completed one since qualifying. I found it demoralising that I had qualified with an additional skill I could not utilise and believe that given that I had qualified with NIPE, I should have been able to utilise it alongside my midwifery skills as it is of benefit to women, babies and midwives alike" (NQM 3).

\section{Utilising skills in practice}

There was a mixed response as to whether the participants had been encouraged to use their skills during their preceptorship; if they could maintain their competence and the guidance they received from their employer on maintaining competence (Table 4).

\section{In colour please}




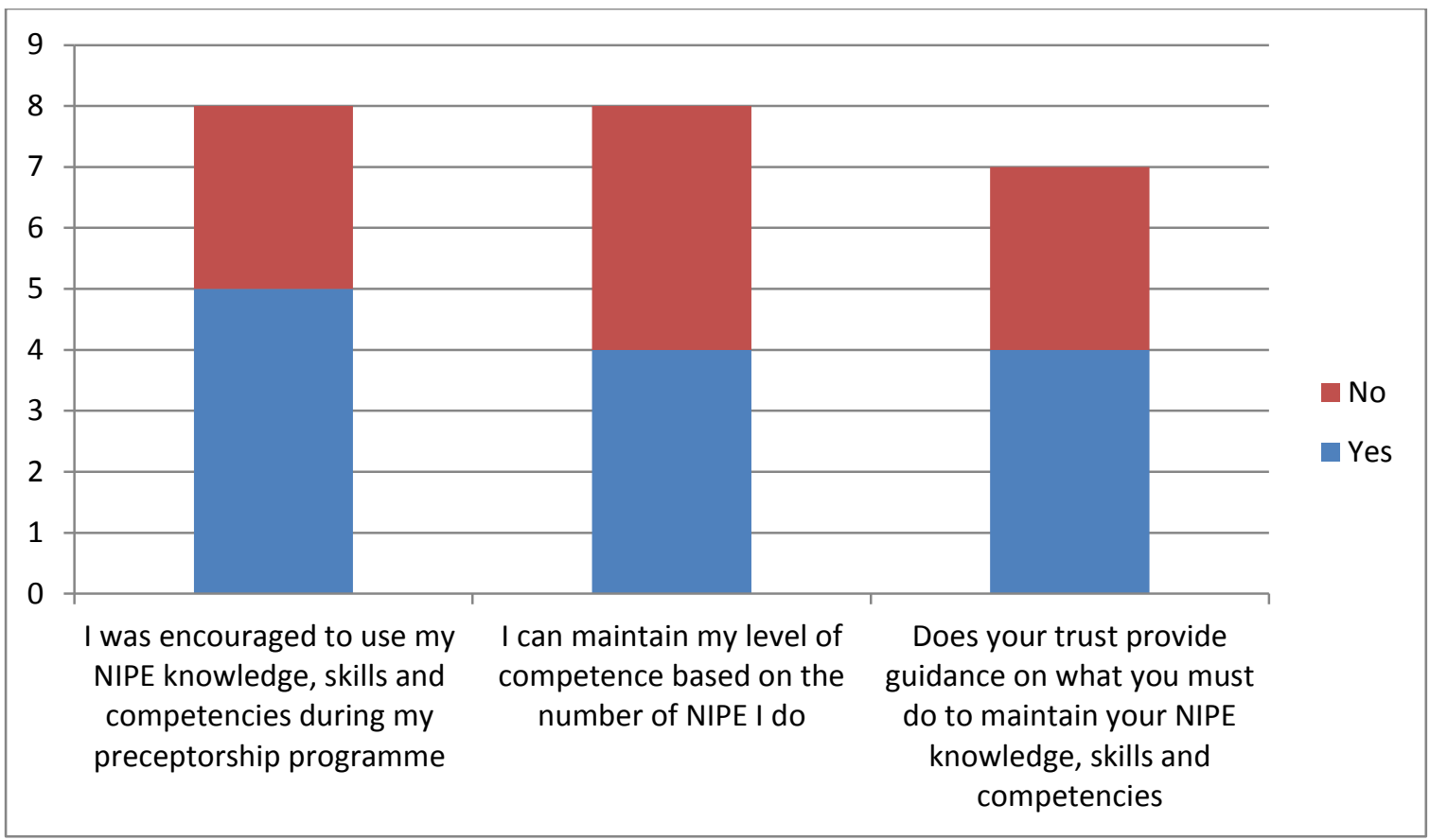

Table 4: Utilising skills in practice

An open text box was provided for participants to elaborate on their responses and six gave more detail about the guidance from the Trust to maintain their NIPE knowledge skills and competences. These ranged from no guidance at all to annual updates that included peer review and forums for discussion. The sixth respondent reported that midwives where she worked were not allowed to formally undertake NIPE, but she still completed the examination as part of her role as a practising midwife in order to maintain her skills.

Finally, the participants were provided with several options to identify how they would prefer to maintain their competence in practice. Responses identified a shared process such as formal learning from the university (conference and updates) complimented by in-house training and local forums that includes information about mentoring future NIPE students. 


\section{Frequency of examinations}

When participants were asked how often they were currently undertaking NIPE the responses were varied from weekly to not at all. No participant was performing the examination every day.

\section{Discussion}

The aim of this study was to evaluate the impact and effectiveness of offering NIPE knowledge and skills to undergraduate student midwives as an extra-curricular activity (ECA). Although this was a small study it offers an insight into the feasibility of a group of motivated and academically achieving students to be NIPE qualified on completion of their undergraduate programme. When the opportunity was offered to students who met the criteria, there were more eligible students than places available demonstrating that they considered this a worthwhile opportunity.

\section{Undergraduate experience}

Despite the identified challenges in undertaking the NIPE module alongside full time study the newly qualified midwives valued the experience and would recommend it to other colleagues. Extra-curricular activities (ECAs) aim to enable students to pursue interests outside of a standardised academic context and offer the opportunity to spend time with others who have a similar interest (Thompson et al. 2013). It could be argued that the structure of the NIPE module did not meet the general understanding of an ECA, but it did facilitate students to spend time learning with others they would not naturally spend time with (qualified midwives), who had similar interests (NIPE training). An unintended positive of providing the learning in this way was the opportunity that the students took to ask the midwives about being qualified and some said they would like more shared learning in this way. 
Peer learning is written about at length (Williams and Reddy, 2016, Carey et al. 2018) and is often in the context of students facilitating the learning of other students where knowledge, ideas and experience is shared in a reciprocal way that benefits both groups (Boud et al. 2001). There appears however, to be little evidence in the literature that identifies the benefits and challenges of qualified practitioners and undergraduate students undertaking shared classroom learning. Whilst this appears to be an under researched area there are parallels with practice related knowledge shared between midwifery students and their qualified counterparts. A study by Young (2012) has highlighted that student midwives enhanced their decision-making skills when they were exposed to the discourse around clinical decisions made by midwifery colleagues or their mentor.

From the participants' responses it was evident that the beneficiaries of this model included the students, the employers and the women. Students acknowledged that the course gave them a more in-depth understanding of newborn anatomy and physiology that complimented the learning they had in the undergraduate programme. It is noted that this knowledge was transferable to the initial examination of the newborn and could be used when qualified, even if not NIPE qualified. This finding adds support to Blake's (2012) suggestion of incorporating the NIPE theory within the undergraduate curriculum to deepen the students' understanding of the newborn. Added advantages include aiding conversations with women and their families and enhancing decision-making skills. Blake (2012) goes as far as stating that by not including the additional NIPE screening elements, students are undertaking an incomplete assessment. Furthermore, if students qualify with the NIPE skills it loses its 'expert' label and thus becomes the role of all midwives (Davies, 2008; McDonald 2018). 
Those students who were able to practise the skills once qualified identified that they gained greater job satisfaction through being able to provide continuity of care to the women. This approach supports the recent NHS publication where continuity of care is considered a key feature to enhance the childbirth experience for women (National Maternity Review [NMR], 2016) The newly qualified midwives' comments also highlighted how an in-depth understanding of the skills required to perform the NIPE increased awareness of poor practice. Recognising poor practice provides the opportunity to raise this as a concern and address it, so the women and their babies are protected from harm (NMC 2015; 2017).

Although the employers were not surveyed, it is evident from the responses that they benefitted from newly qualified midwives being able to provide NIPE assessments. However, this raises the question why only just over half of the newly qualified midwives reported being facilitated to consolidate these skills during their preceptorship programme. It was particularly concerning that one of the respondents reported being required to be reassessed by a paediatric registrar. Davis and Elliman (2008) state that the professional qualification of the person undertaking NIPE is of less importance than being appropriately trained and maintaining competence. In this study, the students were exposed to the same training and education as their registered counterparts which follows national NIPE pathways and standards (National Screening Committee [NSC], 2008). Currently however, the standardisation of the practical elements of the NIPE programme is deemed to be outside of the screening pathway and has been removed from the updated national standards (J. Walker, personal communication, 7 February 2017).

To address this locally, practice partners were involved in developing the content and assessment of the module, which has at its heart, a clinical competency 
assessment tool (CAT) created at the request of the UKNSC (X and Lomax, 2012). All those completing the module are required to utilise the CAT when examining newborn babies thus ensuring a level of standardisation of practice. As this module follows a recognised set of standards and a robust assessment process can be evidenced, NHS organisations should have confidence that the NQMs are safe and effective in their role and not require further assessment.

\section{Recruitment and selection}

The participants acknowledged that having the NIPE skill was an advantage during their recruitment and selection process, however it is difficult to know whether this enhanced their employability as all students within the clinical area of this university tend to get jobs at the point of qualification. Nationally however, there has been a reduction in CPD funding and maternity services managers are finding it difficult to release staff to attend courses such as NIPE (Jones and Furber 2017), therefore, employing newly qualified midwives already skilled in NIPE would mitigate against these potential barriers.

\section{Maintaining Competence:}

Not all respondents were facilitated to use their NIPE skills during their preceptorship neither did all receive guidance from their employer as to how to maintain competence. Findings from a survey undertaken by Yearly et al. (2017) has demonstrated that preparing and training undergraduate student midwives to complete NIPE met both service needs and an evolving maternity service. Other benefits revolved around equipping midwives to work in more contemporary ways (Jones and Furber, 2017; Yearley et al. 2017). In view of the some of the perceived advantages of preparing students to undertaken NIPE at the point of entry into the midwifery profession, it must be queried as to why they are not being facilitated to 
use their skills. These findings are not unlike those of other studies where several factors impacted on skills maintenance such as workload, lack of recognition of role and support from management (McDonald, 2008). Failure to utilise the skills of NIPE practitioners will result in their confidence and competence diminishing including becoming deskilled in NIPE (Steel 2007; Lanlehin et al. 2011; Rogers et al. 2017).

Providers of NIPE screening are advised to have a system in place to assess ongoing competency in undertaking the NIPE examination, therefore there needs to be a commitment from the Trusts to ensure midwives keep up to date (PHE 2017/18). Whilst the national screening body recommends newborn examiners undertake the NIPE online e-learning resource on an annual basis, midwives responding to this survey favoured maintenance of skills through a collaboration between the university and clinical practice. Interestingly, the midwives wanted students to be undertaking this skill during practice to enable them to maintain their skills.

\section{Limitations}

It is recognised there are a number of limitations to this study. As places on this course were limited to 15 over a three-year period this could only be a small study and therefore results cannot be generalised. The authors further acknowledge that it would have been useful to include the experiences of those qualified midwives who undertook the NIPE programme alongside the participants who contributed to this study. In addition, the authors acknowledge that the survey did not utilise a validated tool, but the questions were constructed to respond to a particular set of questions the research team wished to explore in more detail, thus achieving the aims and objectives of the study. 


\section{Recommendations for higher education and Implications practice}

Our recommendations for higher education are:

- Delivering NIPE as an extra-curricular activity is a feasible option

- There are benefits to introducing NIPE related theory into the undergraduate programme, even if it is not feasible to assess competence due to lack of qualified NIPE practitioners, so this should be considered

It has been highlighted that incorporating both theory and practice into the undergraduate programme is currently restricted because of the lack of NIPE mentors/assessors in practice. However, this study has shown the potential benefits to both the employer and the women, and would therefore suggest it would be in the interest of the employer to collaborate with the university to find ways of increasing NIPE assessors in order fully implement NIPE training within the undergraduate programme.

\section{Conclusion}

This small study demonstrates the feasibility of providing NIPE as an extra-curricular activity to students undertaking a standard undergraduate midwifery programme and highlights a useful way of embedding an educational initiative that is not within a standard midwifery curriculum. All those who completed the questionnaire agreed that this learning should be undertaken whilst still a student. The benefits identified were not just for the midwife herself, but also for the women and their employer. The midwives felt their confidence, knowledge and skills around neonatal issues had increased, women experienced better continuity of care and employers benefitted from the increased number of people who could undertake this assessment. Finally, the extracurricular training offered a practical solution to increasing the local workforce skilled in NIPE before the validation of a new curriculum in 2019. Further 
research exploring the views of the qualified midwives who study alongside undergraduate students would enhance the potential for further collaborative learning.

\section{References}

Australian Nursing and Midwifery Accreditation Council, 2014. Midwife Accreditation Standards. Available at:

https://www.anmac.org.au/sites/default/files/documents/ANMAC_Midwife_Accreditati on_Standards_2014.pdf. Accessed date: 5 November 2019.

Blake, D., 2012. Newborn examination: The student's role? British Journal of Midwifery 20 (12), 892-896.

Boud, D. Sampson, J. Cohen, R., 2001. Peer Learning in Higher Education: learning from and with each other. Kogam Page, London.

Carey M. Chick A. Kent B and Latour J. 2018. An exploration of peer-assisted learning in undergraduate nursing students in paediatric clinical settings: An ethnographic study. Nurse Education Today 65, 212-217.

https://doi.org/10.1016/j.nedt.2018.03.014

$X$ and Lomax, A., 2013. NHS UK Screening Committee, Newborn and Infant Physical Examination (NIPE): The Competency Tool. Study NIPE Educator's Study Day Presentation: $4^{\text {th }}$ March 2013, London.

Creswell, J.W., Poth, C.N., 2018. Qualitative Inquiry and Research Design: Choosing Among Five Approaches. SAGE, Los Angeles.

Davies, L., 2008. Examination of the newborn: a holistic approach. The Practising Midwife 11 (4), 24-25. 
Davis, A. and Elliman, D., 2008. Newborn examination: setting standards for consistency. Infant 4 (4), 116-120.

Department of Health, 2007. Maternity Matters: choice, access and continuity of care in a safe service. Department of Health, London.

Department of Health, 1993. Changing childbirth, part 1: report of the Expert Maternity Group. HMSO, London.

Edwards, PJ., Roberts, I., Clarke, MJ., DiGuiseppi, C., Wentz, R., Kwan, I., Cooper, R., Felix, LM., and Pratap, S., 2009. Methods to increase response to postal or electronic questionnaires. Cochrane Systematic review. Available from: https://doi.org/10.1002/14651858.MR000008.pub4

Hall, D.M.B., and Elliman, D., 2006. Children for Health. 4th ed. Oxford University Press, Oxford

Hall, D.M.B., 1999. The role of the routine neonatal examination. British Medical Journal 318, 619-620. doi: http://dx.doi.org/10.1136/bmj.318.7184.61 Holloway, I.,2008. A-Z of qualitative research in healthcare. second ed. Blackwell, Oxford.

Ireland, J. and van Teijlingen E. 2013. Normal birth: social-medical model. The Practising Midwife 16 (11), 17-20.

Jones, T. and Furber, C., 2017. The Newborn Infant Physical Examination: Incorporating the theory into midwifery education. British Journal of Midwifery 25 (9), 593-597.

Lanlehin, R., Noble, H. and McCourt, C., 2011. How well do midwives use skills and knowledge in examining newborns? British Journal of Midwifery 19 (11), 687-691.

Lomax, A., 2001. Expanding the midwife's role in examining the newborn. British Journal of Midwifery 9 (2), 100-102. 
McDonald, S., 2018. Integration of examination of the newborn into holistic midwifery practice: a grounded theory study. Evidence Based Midwifery 16(4), 128-135.

McDonald, S., 2008. Examining a newborn baby: are midwives using their skills? British Journal of Midwifery 16 (11), 722-724.

McCue, C., 2015. Data Mining and Predictive Analysis: Intelligence gathering and crime analysis $2^{\text {nd }}$ edn. Butterwort-Heinemann. https://doi.org/10.1016/C2013-000434-3

McFadden, A. and Paterson, L., 2005. Examination of the Newborn: A Survey of Training Courses in England. University of Teeside and South Tees Hospitals NHS Trust. Unpublished.

Midwifery Council of New Zealand, 2015. Standards for approval of pre-registration midwifery education programmes and accreditation of tertiary education organisations [online]. Available from:

https://www.midwiferycouncil.health.nz/sites/default/files/professionalstandards/Midwifery_Standards_2015_web_final.pdf

National Institute for Health and Care Excellence., 2006. Postnatal care up to 8 weeks after birth. Available from: https://www.nice.org.uk/guidance/cg37

National Maternity Review, 2016. Better births: improving outcomes of maternity services in England. A five year forward view for maternity care. National Maternity Review, London. Available from: https://www.england.nhs.uk/wpcontent/uploads/2016/02/national-maternity-review-report.pdf

Nursing and Midwifery Council., 2017. Enabling Professionalism in Nursing and Midwifery Practice. Available from:

https://www.nmc.org.uk/globalassets/sitedocuments/other-publications/enablingprofessionalism.pdf?_t_id=1B2M2Y8AsgTpgAmY7PhCfg\%3d\%3d\&_t_q=enabling+p rofessionalism\&_t_tags=language\%3aen\%2csiteid\%3ad6891695-0234-463b-bf74- 
1bfb02644b38\&_t_ip=95.149.98.126\&_t_hit.id=NMC_Web_Models_Media_Docume ntFile/_9a081007-d29a-4658-a29a-edc6ebc692e9\&_t_hit.pos=2

Nursing and Midwifery Council., 2015. Standards for pre-registration midwifery education. Available from:

https://www.nmc.org.uk/globalassets/sitedocuments/standards/nmc-standards-forpreregistration-midwifery-education.pdf

Nursing and Midwifery Council., 2009. Standards for competence for registered midwives. Available from:

https://www.nmc.org.uk/globalassets/sitedocuments/standards/nmc-standards-forcompetence-for-registered-midwives.pdf

National Screening Committee, 2008. NHS Newborn and Infant Physical Examination Standards and Competencies. NSC, London.

Public Health England., 2016. Newborn and Infant Physical Examination Screening Programme Handbook 2016/17. Department of Health, London.

Public Health England., 2017/2018. NHS public health functions agreement 201718, Service specification No.21 NHS Newborn and Infant Physical Examination Screening Programme. Available from: https://www.england.nhs.uk/wpcontent/uploads/2017/06/service-specification-21.pdf.

Rogers, C., Yearley, C. and Jay, A., 2017. Education provision for the newborn physical examination as a post-registration module: National survey. British Journal of Midwifery 25 (2), 88-92.

Stanyer, R., and Hopper, H., 2019.Is the incorporation of the newborn examination in the pre-registration curriculum acceptable in clinical practice? A qualitative study. Nurse Education in Practice 35, 117-123.

Steel, D. 2007. Examining the newborn: why don't midwives use their skills. Midwifery 15 (12): 748-52. 
Sue, V.M., and Ritter, L.A. 2012, 'Planning the online survey', in Conducting online surveys, 2nd edn, SAGE Publications, Inc., Thousand Oaks, CA, pp. 14-32, [Accessed 4 November 2019], doi: 10.4135/9781506335186.

Thompson, L.J., Clark, G., Walker, M., Whyatt, J. D., 2013. 'It's just like an extra string to your bow': Exploring higher education students' perceptions and experiences of extracurricular activity and emplyability. Active Learning in Higher Education 14 (2), 135-147.

Townsend, J., Wolke, D., Hayes, J., Dave, S., Rogers, C., Bloomfield, L., QuistTherson, E., Tomlinson, M. and Messer, D., 2004. Routine examination of the newborn: the EMREN study. Evaluation of an extension of the midwife role including a randomised controlled trial of appropriately trained midwives and paediatric senior house officers. Health Technology Assessment 8 (14).

Williams B. and Reddy P. 2016. Does peer-assisted learning improve academic performance? A scoping review. Nurse Education Today 42, 23-29. doi.org/10.1016/j.nedt.2016.03.024

Yearley, C., Rogers, C. and Jay, A., 2017. Including the newborn physical examination in the pre-registration midwifery curriculum: National survey. British Journal of Midwifery 25 (1), 26-32.

Young, N., 2012. An exploration of clinical decision-making amongst students and newly qualified midwives. Midwifery 28, 824-830. 